\title{
«ПРАКТИКА ЗАБОТЫ» ЛУИДХИНЫ МОРТАРИ КАК СОЦИОЛОГИЧЕСКИЙ ПАЗЗЛ
}

Обзор посвящен анализу концепции итальянского философа Луиджины Мортари, развивающей идеи Хайдеггера о заботе как фундаментальном компоненте человеческого существования. Этот сюжет может выступать ресурсом объяснения социального, учитывая беспрецедентность масштабов необходимой людям как биологическому виду заботы друг о друге, от материнского внимания до некоторых форм разделения труда. Согласно Мортари, забота (care) подразумевает удовлетворение таких потребностей Другого, которые тот не способен удовлетворить самостоятельно, в противном случае речь идет об обслуживании (service), при этом предметом подлинной заботы может быть лишь удовлетворение жизненно важных потребностей. Долгое время забота как самостоятельная ценность оказывалась на периферии исследовательских интересов, предпочтение отдавалось идеологически более привлекательной автономности; однако человек лишь часть жизни проводит в состоянии автономии, и в этот период обычно сам выступает источником заботы. Отсюда критика Мортари либерального взгляда на автономность как цель и ключевую ценность, а не один из этапов жизни, что открывает перспективы понимания недостижимости автономии кроме как ценой разрушения социального. Однако критика либеральной модели автономности может иметь нежелательные политические последствия, оборачиваясь оправданием патернализма и тоталитаризма. Дополнительную сложность Мортари обнаруживает в неформализуемости заботы о Другом из-за его принципиальной непознаваемости, что налагает на заботящегося особую ответственность. Например, быть хорошей медсестрой не означает строгое соблюдение должностных инструкций - необходимые компетенции нарабатываются опытным путем - благодаря переосмыслению случаев из практики. Мортари утверждает, что забота обесценена и не вознаграждается адекватным образом потому что это женская функция, но допустимо предположить, что основную роль здесь сыграла ее неизмеряемость и неформализованность. Идеализируя заботу как одаривающее действие, в своей критике моссовской концепции дара, Мортари игнорирует функции дара по сборке социального.

Ключевые слова: забота, автономность, социальное, реляционная онтология, дар, гендер

DOI: 10.17323/727-0634-2017-15-3-465-476

Антон Александрович Смолькин - к.с.н., зав.кафедрой гуманитарных дисциплин Института общественных наук РАНХиГС; научный сотрудник МВШСЭН, Москва, Россия. Электронная почта: anton.smolkin@gmail.com 
Книга Луиджины Мортари «Практика заботы» вышла на итальянском языке в 2006 году, издана на русском десять лет спустя. С того времени Мортари написала еще две книги - «Заботу о себе» (Mortari 2009) и «Философию заботы» (Mortari 2015) - однако они не переведены. В «Практике заботы» не рассматривается забота о себе, а только забота о других. Хотя, как мы увидим далее, для Мортари забота о себе - важный элемент заботы о ком-то еще. «Практика заботы» является введением в проблему, построенным на анализе заботы в этико-прикладном и педагогическом контексте, и систематического обзора - исторического или теоретического - не содержит. Не стоит, однако, обвинять или недооценивать автора - Мортари стала заложницей глубины темы и авторитета теоретических опор, например, Хайдеггера. Это, впрочем, не оправдывает то, что автору не удалось остаться теоретически последовательной и получился не цельный текст, а скорее сад теоретических камней. Этот упрек не случаен, и название книги не должно вводить в заблуждение - в ней ничего не говорится о собственно практике. Мортари несколько раз упоминает о результатах собственных эмпирических исследований, но никаких цифр, цитат или ссылок не приводит, лишь единожды кратко пересказывая выводы (Мортари 2016:217), в целом же книга посвящена философским и этическим обоснованиям практик заботы. Поднимаемые Мортари вопросы дают множество поводов к размышлению и представляются настолько фундаментальными, что от книги невольно начинаешь ждать слишком многого. Она может дать пищу для рефлексии педагогам и социальным работникам, но, предположу, едва ли будет интересна философам. Принять решение, следует ли обращаться к ней социологу, надеюсь, поможет этот обзор. Социологических работ о теории заботы написано меньше, чем следовало бы. О чем свидетельствует хотя бы тот факт, что соответствующая терминология в российской научной традиции не стала общепринятой: как, например, переводить caregiver - заботящийся? человек, практикующий заботу? Наконец, нельзя не отметить, что Мортари говорит о чем-то очень близком социологу, хотя и на другом языке, позволяя взглянуть на социологические проблемы через иную оптику.

\section{Концепт заботы}

Введение концепта заботы может внести вклад в ремонт теоретической социологии, если традиционно понимать ее как дисциплину, призванную в первую очередь объяснять взаимодействие людей. Без концепта заботы ряду социологических субдисциплин, таких как социология возраста или исследования инвалидности, заметно недостает объяснительного потенциала. Забота оказывается компенсационным механизмом, помогающим функционировать индивидам с ограниченной биоавтономностью. Более того, без идеи заботы принятые объяснения способов устроения общества грозят увязнуть в экономизированной и рационализированной «социологии 
домохозяйств», не заглядывая внутрь «теплых отношений» и не пытаясь подступиться к тому, что представляется слабо измеряемым. Разумеется, мы знали о заботе не только до Мортари, но и до Хайдеггера или Фуко но как о нерефлексивном элементе, едва ли не элементе биосубстрата социального в виде, например, «материнского инстинкта».

Проблема социологических перспектив исследований заботы состоит в том, что она слабо концептуализирована, но при этом имеет традиции теоретического описания в этике, философии и биологии. Междисциплинарные интеграции традиционно проблематичны и не всегда удачно встраиваются в теоретизирование в области социальных наук. Здесь показателен пример социобиологии - самоочевидная идея, до сих пор не нашла перспективных способов взаимодействия с актуальной социологической теорией. Ключевые работы по социобиологии содержат набор убедительных фактов, способных приостановить экспансию социального конструкционизма, но не более того (Уилсон 2015). Однако очевидно, что незыблемость «догибридного» порядка стала проблематичной - социальным дисциплинам все сложнее игнорировать успехи естественных наук в вопросах изучения мозга, влияния генов на поведение человека.

\section{Забота как конститутивный элемент человеческого}

Забота, по словам Мортари, «традиционно упускалась из внимания» исследователями, поскольку западная философская традиция считала уязвимость - фундаментальную причину необходимости заботы - «невыносимой» и неохотно мирилась с таким положением дел. По этой причине в фокусе внимания философов оказываются неподвластные времени или обстоятельствам явления, а забота остается на периферии исследовательских интересов. Являясь одной из фундаментальных человеческих характеристик, она оказывается «неудобной» для исследования.

Мортари обосновывает заботу как фундамент человеческого через идею «вот-бытия» Хайдеггера, поскольку она образует смысл вот-бытия: «путь к подлинности индивида лежит через заботу» (Мортари 2016: 13). Существование по своей сути является заботой о существовании, его неустранимым условием, и человеку приходится тревожиться о своей и других жизнях буквально «не зная в этом передышки» (Там же: 55$)^{1}$. Забота, проявляясь в активной или в пассивной форме, неизбежно занимает большую часть человеческой жизни, поскольку человек не автономен, не самодостаточен и не может сам по себе быть источником смысла своего существования. Человек нуждается как в том, чтобы быть объектом заботы,

\footnotetext{
${ }^{1} \mathrm{Cp}$. со значением слова «беззаботный» в русском языке, означающее в нашем контексте те (редкие) моменты, когда бремя волнений о существовании временно тебя покидает.
} 
так и в том, чтобы заботиться, выступать субъектом практик заботы, в том числе и о самом себе.

Мы, разумеется, не можем свести это к небиологическому рассуждению о биологическом, поскольку хайдеггерианская «хрупкость вот-бытия» состоит не в физиологической конечности, а в его (принципиальной) незавершенности (Хайдеггер 2002). Вот-бытие - бытие-заброшенным, в котором фундамент вот-бытия заложен не им самим, говорит о тяжком бремени, довлеющем над вот-бытием. Чувство своей ограниченности возможностью бытия, которая принадлежит нам, но предоставлена нам не нами самими, заставляет воспринимать существование как долженствование (см. раздел «Долг дара»), давлеющее над сознанием и тем самым порождающее тревогу. В этом модусе заботы необходимость предстает чем-то претерпеваемым, а не принимаемым, и, следовательно, такая забота не свободна. Неизбежная необходимость заботы может стать значимым ресурсом объяснения социального, учитывая беспрецедентность масштабов необходимой людям заботы друг о друге от материнского внимания до некоторых форм разделения труда.

\section{Определение заботы}

Согласно Мортари, забота (саre) подразумевает удовлетворение таких потребностей Другого, которые тот не способен удовлетворить самостоятельно, в противном случае речь идет об обслуживании (service). При этом «предмет подлинной заботы» - удовлетворение «жизненно важных потребностей», поэтому обычно речь идет о необходимости помощи «в разумных пределах». Отдельно оговаривается, что в отсутствие человеческого контакта никакая практика не может определяться как забота, поскольку последняя «сущностным образом основана на отношениях» (Мортари 2016: 46).

Кроме того, заботящийся уязвим перед лицом возможных злоупотреблений в силу его «сердечного» отношения к Другому, и поэтому он должен заботиться также и о себе. Эта уязвимость не может быть устранена полностью; она сохраняется в силу своей фундаментальной социальной природы - уязвимость есть следствие взаимозависимости. Соответственно, преданность не следует приравнивать к жертвенности, поскольку первая подразумевает потерю себя. Забота как преданность предполагает, что субъект умеет заботиться о другом благодаря тому, что уже заботится о себе и действует, сохраняя себе верность.

Чтобы отношения можно было определять как заботу, объект последней должен быть знаком заботящемуся и иметь для него некоторое значение; тогда забота может иметь место даже на расстоянии. Помощь далеким от нас и незнакомым нам людям, по Мортари, следует определять как солидарность, а не как заботу - хотя автор книги оговаривается, что Ноддингс и Боуден называют это диффузной формой заботы. Забота такого 
типа является необходимой предпосылкой справедливости и питается чувством сострадания. При этом забота все же не исключает посторонних, поскольку в идеале подразумевает открытость и готовность помогать всем, кто выказывает потребность в помощи, однако «заботятся не о многих одновременно, а о каждом человеке с его специфическими потребностями» (Мортари 2016: 47).

Мортари разделяет заботу на «восстановительную» (на мой взгляд, уместнее было бы использовать более широкий термин - компенсационную, поскольку не всегда можно добиться восстановления; выбор термина у Мортари здесь - по-видимому, политический выбор педагога-оптимиста), подразумевая уход за больными, пожилыми и инвалидами, и «развивающую практику», предполагающую педагогическое измерение. В английской терминологии это, соответственно, cure и care, хотя Мортари отдельно отмечает, что в последнее время в медсестринской практике саre порой понимают в более широком значении, включающим и некоторые аспекты cure. Забота, соответственно, может включать в себя весьма широкий набор действий - это и работа по восстановлению временно или постоянно утраченной автономии, и развитие навыков заботы о себе.

\section{Причины заботы}

Причины заботы Мортари постулирует через другое ее определение: «когда процесс раскрытия смысла жизни Другого одаривает смыслом и нашу собственную жизнь, тогда имеют место отношения заботы» (Там же:49), и, таким образом, «в заботе раскрывается главное, что есть в жизни» (Там же:219). Для Мортари заботливость - это модус вот-бытия-с-другими, который не следует логике долженствования, а обнаруживает свою причину в переживании необходимости действий, требующихся Другому. Поэтому забота о потребностях Другого не требует логических обоснований и не нуждается во внешнем признании, принося удовлетворение сама по себе.

Пытаясь найти основания понятым таким образом причинам заботы, Мортари вынуждена в итоге обратиться к представлениям Ноддингс о «естественной заботе» (natural caring) (Там же: 220) ${ }^{1}$. Показательно, что далее этот сюжет не развивается, потому что следующим шагом должно быть обращение к эволюционной этике. Если Мортари говорит о сущностных, онтологических элементах поведения, которые люди «находят в самих себе», безотносительно уровня рефлексивности или образования, то обращение к эволюционным аргументам, возможно, не единственный, но достаточно надежный путь, хотя и с определенными политическими препятствиями.

\footnotetext{
1 Показательно, что сама Ноддингс связывает этот термин именно с отношениями матери и ребенка (Noddings 1984: 5).
} 


\section{Критика автономности-как-цели}

Итак, человек лишь часть жизни проводит в состоянии, которое можно считать автономным - и в этот период обычно сам выступает источником заботы. Мортари соглашается с тем, что ключевая причина недостатка автономности, как правило, физиологическая: забота о теле/мозге (сознании), либо еще не достигших автономии, либо уже утративших некоторые из своих функций. Дети становятся объектом заботы в силу того, что еще не достигли состояния автономии, которое требуется для заботы о самих себе (культурная обусловленность этого концепта и определяет исторически подвижные границы детства); пожилые люди нуждаются в заботе, поскольку постепенно утрачивают автономность, больные утрачивают ее лишь на время.

Отсюда вырастает критика либерального взгляда на автономность, понимающего ее как цель и ключевую ценность, а не как один из этапов жизни:

До тех пор, пока этическая теория не освободится от либеральных предпосылок, отдающих предпочтение независимости и автономии, и не будет переформулирована на основе культуры заботы (со-зависимости), в соответствии с которой люди прежде всего «зависимы от» и «уязвимы», по-настоящему человечная этика попросту невозможна (Мортари 2016: 198-199).

Мортари при этом признает, что было бы неконструктивно отвергать независимость как жизненную ценность. Развивая ее позицию, отмечу, что при этом необходимо отдавать себе отчет в недостижимости полной автономии кроме как ценой разрушения социального. Следует, однако, учесть, что критика либеральной модели автономности в пределе может иметь нежелательные политические последствия, оборачиваясь оправданием патернализма и тоталитаризма. Возможно, имплицитно именно с этим связан упор на автономность в политической философии, не говоря уже о том, что это лучше сочетается с демократическими ценностями, правами человека и поисками идентичности.

\section{Реляционная онтология}

Какой бы ни была теоретическая альтернатива автономности-как-цели, она должна иметь фундаментом осознание и признание того, что мы всегда в долгу перед Другими. На аксиоме фундаментальности заботы построена реляционная онтология, исходящая из предпосылки, что мы не существуем «в единственном числе». Наше бытие обретает форму из отношений, в которых мы пребываем: «мы представляем собой отношения, выстраивающие поле нашей жизни, а следовательно, неотличимы от отношений, которые 
нас формируют и которые мы, в свою очередь, формируем» (Там же: 116). Отсюда тезис об онтологии недостаточности, констатация положения человека как множественного в своей единичности (читай: социального) существа. При этом мы, хотя и не можем избежать отношений с другими, все же остаемся радикально обособленным. Следовательно, мы можем говорить о принципиальной невозможности полной автономии (и, повторюсь, невозможности общества, составленного из таких индивидов), и именно в силу осознания этой онтологической недостаточности мы заботимся об отношениях, потому что буквально собраны из отношений, в которых пребываем, формируя их и формируясь под их влиянием.

Заботящийся действует «одновременно-для-себя-и-для-других», так как реляционная онтология предполагает, что индивидуальное благополучие вот-бытия невозможно. Более того, по Мортари, в реляционной онтологии даже сами термины альтруизм и эгоизм не имеют смысла - хотя точнее было бы сказать «работают непривычным нам образом» - например, с позиций эволюционной этики непонятно, почему описанное выше нельзя определять как разновидность группового альтруизма. Однако, при этом видеть во внимании к Другому опасность потери самости «абсолютно необоснованно» (Мортари 2016: 118), хотя ранее в тексте книги и говорилось об уязвимости заботящегося.

Понимание Другого как священного подталкивает нас к бескорыстному действию в ответ на потребность в помощи, выражаемую другим. При этом Мортари не останавливается на анализе истоков священного статуса Другого, но можно предположить, что священное надо понимать как подразумевающее вечный, невозвратимый долг перед другими. Мы посмотрим пристальнее на звенья этой запутанной логики в заключительном разделе «Долг дара». Здесь Мортари возвращается к мотиву преданности, основанной на понимании Другого как священного, сравнивая ее преданность с «притяжением к совершению действия, что отличается от совершения действия под давлением груза» (Там же: 60). Эта метафора представляется не вполне ясной (невольно вспоминаются «законы социального тяготения» Сен-Симона): что, собственно, имеется в виду - что такое принуждение «привычно» и «естественно», потому что у него нет внятного субъекта принуждения - иными словами, оно «социально»?

\section{Неформализованность}

Действуя для Другого, мы регулярно оказываемся в тупиках или даже обнаруживаем, что движемся «не в ту сторону» (полагаю, это следует относить и к заботе о себе, ведь «я» в будущем - это тоже Другой). Мортари раскрывает неразрешимую фундаментальность этой ситуации цитатой из Левинаса: «Если бы можно было овладеть другим, ухватить и познать его, то он не был бы другим. Обладание, познание, схватывание - сино- 
нимы власти» (Там же: 143). В познании Другого невозможно продвинуться без его стереотипизирования, и дело здесь не просто в неточности нашего знания, а в принципиальной неуловимости Другого: «Познание рассматривается как постижение индивида "не в его своеобразии, которому не придается значения, а во всеобщнсти, которая только и доступна науке (Левинас)"» (Мортари 2016:224). В том числе и поэтому у Мортари регулярно возникают проблемы с определением заботы - ведь это забота о Непознаваемом,- вследствие чего приходится регулярно уточнять, сдвигать фокус, едва ли не переопределять отношения заботы.

Поскольку «понимание другого всегда смутное, нечеткое, временное» (Там же: 143), радикально недостаточное, невозможно предложить универсальные, ясные и последовательные алгоритмы для реализации заботы. В таких ситуациях важна обратная связь в виде жеста, улыбки, чтобы можно было понять, то ли ты делаешь, и Мортари даже предлагает в рамках программ по подготовке специалистов в области заботы организовать лаборатории, «ориентированные <.. > на анализ эмоционального опыта» (Там же: 111).

Следовательно, невозможны предустановленные правила, позволяющие автоматически решать проблемы, которые возникают в процессе проявления заботы. Можно возразить, что принятие этически нагруженных решений исходя из контекста подразумевает высокую степень произвольности, на что Мортари приводит контраргумент Хельд, что подводить частный случай под абстрактный принцип не менее рискованно.

Невозможность полного контроля над процессом налагает на заботящегося радикальную ответственность, поскольку любая ошибка может иметь непредсказуемые последствия: «вырезая скульптуру, ты точно представляешь, какое усилие надо применить, но действия в отношениях совсем не таковы» (Там же: 213). Осознание уязвимости Другого приводит к «потребности в уважении» к нему. Мортари иллюстрирует это конфликтом, с которым сталкивается медсестра, выбирая между уважением к автономии пациента и ответственностью за назначение правильного лечения. Вспоминая еще одно замечание Мортари («В отношениях всегда присутствует некая форма власти, и в асимметричных отношениях она "выступает критическим элементом", поскольку сосредоточена на одном полюсе» (Там же: 63)), любопытно было бы провести параллели с эволюцией принципов международной политики - как, когда и при каких обстоятельствах допустимо вмешательство в дела другого государства? Отсюда общий принцип: в процессе заботы важно не разрушить суверенитет Другого. Мортари описывает это как «не-делающее-действие» (Там же: 156), «быть максимально присутствующим при отсутствии себя» (Там же: 159), особый способ видеть другого, участливое внимание. Мортари называет это пассивной установкой заботы - тактичное присутствие, невмешательство в Другого. 


\section{Гендер и забота}

Мортари утверждает, что за последние несколько столетий западная патриархальная культура дискредитировала все аспекты и практики, связанные с феминностью. Означает ли это, что более ранняя ситуация может быть признана удовлетворительной, не разъясняется. Самые интересные страницы этой сюжетной линии, впрочем, посвящены именно заботе. С одной стороны, Мортари пишет, что «забота не должна восприниматься как биологически предопределенное явление (здесь и далее выделение мое), как если бы она была исключительно прерогативой женщин» (Мортари 2016:34), а «труд, связанный с заботой, необоснованно рассматривался как естественный» (Там же:28). С другой - «женщины в большей степени, чем мужчины, осознают онтогенетическую ценность заботы», «осознают ее первостепенную важность» (Там же: 34), и потому выбирают непростые роли ради благополучия других. Откуда берется это гендерно предопределенное осознание? Мортари подчеркивает, что женщинам прямо и косвенно прививают понимание, что именно в заботе они могут обрести смысл жизни. В результате многие, занятые практиками заботы, тем самым «отождествляют себя с символическим порядком, отличающимся от доминирующего» (хотя, как предполагается, могли бы найти более статусные/выгодные варианты занятости), имеют иную иерархию ценностей, благодаря чему и «обретают тот смысл вот-бытия, в поисках которого пребывали и который не могла им дать ни одна форма власти» (Так же:40). Иными словами, патриархальное общество воспитывает женщин таким образом, чтобы они были склонны посвятить себя заботе, но парадоксальным образом именно в этом и обнаруживается способ «реализации вот-бытия женщин».

Единственное, что могло бы оправдать такой упрек в данном случае подразумеваемая идея, что за навязанную работу можно меньше платить. Мортари, соответственно, делает вывод, что забота обесценена и не вознаграждается адекватным образом именно потому, что ей занимаются женщины. Но не происходит ли это скорее потому, что сама забота неизмеряема и неформализуема? Вся аргументация Мортари в действительности ближе к этому варианту. Это, безусловно, не отменяет проблемы недооценивания, но заметно смягчает ее феминистский акцент.

\section{Материнская и медсестринская забота}

Некоторые формы заботы нуждаются исключительно в символическом признании - такие, как отношения матери и ребенка или родственные и дружеские отношения. Парадигматическими случаями заботы Мортари в первую очередь считает отношения матери и ребенка (Так же: 74), совершенно особые отношения, не имеющие аналогов с точки зрения интен- 
сивности телесного опыта: беременность, роды, вскармливание. Мать не ждет чего-то для себя - она желает полноценного расцвета Другого. То, что переживается ею как благо, определяется благополучием Другого иными словами, фундаментальная этическая направленность практики заботы реализуется в одаривающем действии. Отметим избыточную идеалистичность рисуемой Мортари картины, при том что отцовские отношения она не рассматривает вообще.

Медсестринская забота имеет немало общего с материнской, поскольку получающий такую заботу тоже находится в ситуации зависимости. Главное отличие - не столько в отсутствии личной привязанности, сколько в формализованности этих практик в четко расписанных процедурах. В медицинских учреждениях время обычно распланировано исходя не из субъективных потребностей пациента, а в соответствии с функциональными задачами, стоящими перед персоналом и всей организацией в целом. Соответственно, практика заботы может вступать в противоречие с логикой работы медицинской организации, для которой важны эффективность и экономичность. По своей сути медицинские организации являются предприятиями по восстановлению здоровья, понятому в терминах доказательной медицины, причем в той части, которая может быть регламентирована (см. также: Смолькин 2007). Мортари справедливо видит причину этого в общей ориентации на позитивистскую интерпретацию медицины - а мы едва ли захотим отказываться от строгости и доказательности в научной игре, ставкой в которой являются наше собственное здоровье и жизнь!

Быть хорошей медсестрой не означает действовать строго по должностным инструкциям - практически необходимые медсестре профессиональные компетенции лишь частично зафиксированы в формализованном виде и предстают как знание, которое не поддается освоению на уровне техники, но нарабатывается в процессе опыта благодаря постоянному (пере)осмыслению случаев из практики. Мортари отмечает при этом, что одна из проблем медсестер - как раз чрезмерная личная вовлеченность, которая ведет не просто к эмоциональной перегрузке, но и к соскальзыванию в тотальный контроль над пациентами.

\section{Долг дара}

В логике Мосса дар есть форма обмена, «причем его исконная форма», где «давать» неотделимо от «получать»: подарок обязывает, запуская непрерывный цикл обмена и взаимного признания (Мосс 1996). Однако, сводя дар к одной из экономических форм обмена, Морати игнорирует его работу по сборке социального. В ее тексте забота осуществляется словно в социальном вакууме, без каких-либо статусных последствий или репутационных накоплений для заботящегося. Мортари, строящая свои объяснения на реляционной онтологии, здесь словно бы мыслит отношения- 
взаимозависимости исключительно горизонтально, вне долгого разворачивания во времени - и они из звеньев длинной цепи превращаются в единичные акты заботы.

По Мортари, в заботе, особенно асимметричной, дарение вовсе не подразумевает получения чего-то взамен, это свободный и безвозмездный акт, не подразумевающий моссовской цепочки взаимных обязательств. Одаривающий может искать здесь что-то для себя, но речь не идет о чемто, что другой предоставит ему в ответ - для него главное понять, что его действия дали другому. Следует, однако, напомнить, что наиболее убедительные примеры Мортари (мать-ребенок, групповой альтруизм) имеют явные аналоги у других биологических видов; кроме того, такие отношения часто не подразумевают прямого возврата - межпоколенческий контракт в данном случае скорее предполагает, что главная обязанность не столько вернуть вложенное в вас родителям, сколько инвестировать это в собственных детей. Полагаю, современным социально-философским подходам к заботе и эволюционной этике еще предстоит встретиться - и, хочется верить, эта встреча будет продуктивной.

Если справедливо утверждение о том, что хорошую книгу не столько читают, сколько думают, то работу Мортари следует признать удавшейся. В этом смысле стройная теоретическая модель или готовый исследовательский инструментарий - безусловно, цельный и ценный результат, но часто в меньшей степени побуждающий к самостоятельной рефлексии. «Практика заботы» провоцирует размышления о фундаментальных для теоретической социологии проблемах, на которые не предлагает убедительных ответов возможно, в том числе и потому, что у работ с притязаниями такого масштаба слишком часто оказывается открытый финал.

\section{Выражения благодарности}

Данный текст написан при подготовке научно-исследовательской работы «Социальный статус пожилых людей в практиках повседневного взаимодействия в общественных местах» (2016 г., ИОН РАНХиГС).

\section{Список источников}

Мортари Л. (2016) Практика заботы, СПб.: Алетейя.

Мосс М. (1996) Общества. Обмен. Личность, М.: Восточная литература РАН.

Смолькин А.А. (2007) Медицинский дискурс в конструировании образа старости. Журнал социологии и социильной антропологии, 10 (2): 134-141.

Уилсон Э. О. (2015) О природе человека, М.: Кучково поле.

Хайдеггер М. (2002) Бытие и время, СПб.: Наука.

Mortari L. (2009) Aver cura di sè, Bruno Mondadori.

Mortari L. (2015) Filosofia della cura, Milano: Raffaello Cortina.

Noddings N. (1984) Caring, a Feminine Approach to Ethics \& Moral Education, Berkeley: University of California Press. 


\section{Anton Smol'kin}

\section{'THE PRACTICE Of CARE' BY LUIGINA MORTARI AS A SOCIOLOGICAL JIGSAW}

This review is dedicated to a critical analysis of the Italian philosopher's Luigina Mortari concept of care. Mortari develops Heidegger's ideas on caring as a fundamental component of human existence. This plot can act as a significant resource to explain the social, given the unprecedented scope of the necessary care for people as a biological species about each other, from maternal attention to the division of labour. According Mortari, care means satisfying those needs of the Other, who is unable to satisfy on their own. In other words this is a service, while real care can only be the satisfaction of vital needs. For a long time care as an independent concept was on the periphery of research interests and preference was given to the notion of autonomy, which was seen as more ideologically attractive. However, a person spends only part of their life in a state of autonomy, and during this autonomous period he or she usually acts as a source of care. Mortari criticises the liberal view of autonomy as a goal and key value rather than one stage of life. This opens the possibility to understand the unavailability of full autonomy, except at the cost of destroying the social. However, criticism of the liberal model of autonomy can have undesirable political consequences, such as becoming an excuse for paternalism and totalitarianism. Mortari sees an additional complexity in the informal nature of caring for the Other because of the fundamental unknowability of the latter. This imposes a radical responsibility on the caregiver. For example, being a good nurse does not mean acting strictly according to job descriptions; the necessary competencies are developed in practice due to the rethinking of cases. Mortari argues that care is devalued and is not rewarded adequately not only because it is mainly women engaged in it, but also because of the role played by care unmeasurability and informality. Idealising care as an endearing and giving action and in the criticism of Moss's concept of gift, Mortari ignores the function of the gift in assembling the social.

Keywords: care, autonomy, social, relational ontology, gift, gender

DOI: $10.17323 / 727-0634-2017-15-3-465-476$

\section{References}

Heidegger M. (2002) Bytie i vremia [Being and Time], Saint Petersburg: Nauka.

Mortari L. (2009) Aver cura di sè, Bruno Mondadori.

Mortari L. (2015) Filosofia della cura, Milano: Raffaello Cortina.

Mortari L. (2016) Praktika zaboty [Practice of care], Saint Petersburg: Aleteiia.

Moss M. (1996) Obshchestva. Obmen. Lichnost' [Societies. Exchange. Personality], Moscow: Vostochnaia literatura RAN.

Noddings N. (1984) Caring, a Feminine Approach to Ethics \& Moral Education, Berkeley: University of California Press.

Smol'kin A.A. (2007) Meditsinskiy diskurs v konstruirovanii obraza starosti [Medical discourse in construction of image of old age]. Zhurnal sotsiologii $i$ sotsial'noy antropologii [Journal of Sociology and Social Anthropology], 10(2): 134-141.

Wilson E. O. (2015) O prirode cheloveka [On human nature], Moscow: Kuchkovo pole.

Anton Smol'kin - Kandidat Nauk (PhD) in Sociology, chair of department of humanities, RANEPA; research fellow, MSSES, Moscow, Russian Federation. Email: anton.smolkin@gmail.com 